\title{
AB INITIO STUDY OF CHEMICAL ACTIVATION AND HYDROGENATION OF WHITE PHOSPHORUS IN REACTION WITH RHODIUM TRIHYDRIDE COMPLEX
}

\author{
Iolanta I. Balan*, Natalia N. Gorinchoy \\ Institute of Chemistry, Academy of Sciences of Moldova, Academy str.,3, MD-2028, Chisinau, Republic of Moldova \\ *E-mail: ibalan02@yahoo.com
}

\begin{abstract}
The four-stage mechanism of reaction of the rhodium trihydride complex [(triphos) $\left.\mathrm{RhH}_{3}\right]$ (triphos=1,1,1tris(diphenylphosphanylmethyl)ethane) with the white phosphorus molecule resulting in the phosphane and the cyclo- $\mathrm{P}_{3}$ complex [(triphos $) \mathrm{M}\left(\eta^{3}-\mathrm{P}_{3}\right]$ is analyzed on the basis of ab initio calculations of reactants, products, and intermediate complexes of reaction. It is shown that generation of the transient complex [(triphos)RhH( $\left.\left(\eta^{1}: \eta^{1}-\mathrm{P}_{4}\right)\right]$ followed by intramolecular hydrogen atom migration from the metal to one of the phosphorus atoms is the energetically favourable process. Calculations also show that $\mathrm{P}_{4}$ molecule is activated by coordination to the above complex: the metal-bonded P-P edge is broken, and the tetrahedron $\mathrm{P}_{4}$ is opened to form the butterfly geometry. This activation is realized mainly due to the one-orbital back donation of $4 d$-electron density from the atom of Rh to the unoccupied antibonding triple degenerate $t_{1}^{*}-\mathrm{MO}$ of $\mathrm{P}_{4}$.
\end{abstract}

Keywords: white phosphorus, triphos, rhodium trihydride complex, ab initio calculations.

\section{Introduction}

From the experimental data it is known that the transition metal complexes are efficient in the white phosphorus functionalization processes (see, e.g., reviews on coordination of white phosphorus [1-3] and references therein). These compounds activate the $\mathrm{P}_{4}$ molecule by its oxidation or reduction that leads to the breaking of some bonds in the phosphorus molecule preparing it for further chemical transformations.

As an example of the functionalization of the $\mathrm{P}_{4}$ molecule and of its fragmentation mediated by transition metal complexes can serve the reaction of the trihydride complex [(triphos) $\mathrm{MH}_{3}$ ] (where $\mathrm{M}=\mathrm{Rh}$, Ir and triphos=1,1,1tris(diphenylphosphanylmethyl)ethane, $\left.\mathrm{MeC}\left(\mathrm{CH}_{2} \mathrm{PPh}_{2}\right)_{3}\right)$ with the white phosphorus resulting in the phosphane and [(triphos) $\mathrm{MP}_{3}$ ] complex. On the base of the experimental data it was supposed [4-7] that this process is performed through the next steps (See Scheme 1):

A- the thermal reductive elimination of $\mathrm{H}_{2}$ from $\left[(\right.$ triphos $\left.) \mathrm{RhH}_{3}\right](\mathbf{I})$ and the generation of the transient complex [(triphos) $\mathrm{MH}](\mathbf{I I})$;

B - the oxidative addition of $\mathrm{P}_{4}$ with formation of the hydrido $-\eta^{1}: \eta^{1}-\mathrm{P}_{1}$ complexes [(triphos)MH( $\left.\left.\eta^{1}: \eta^{1}-\mathrm{P}_{4}\right)\right]$ (III);

C - the intramolecular migration of hydrogen atom from the metal to the phosphorus to yield [(triphos)M $\left(\eta^{1}: \eta^{2}-\mathrm{HP}_{4}\right)$ ] (IV);

D - the final addition of hydrogen molecule to the complex IV with the P-P bond cleavage and phosphane separation.

To confirm the possibility of realization of this mechanism it is desirable to study experimentally or (and) theoretically the energy profile of the respective reaction pathway. Some stages of the process indirectly confirmed by experiment. Thus, the conclusion about the formation of the intermediate complex III was based on the reaction of $\mathrm{P}_{4}$ with iridium complex [(triphos) $\mathrm{IrH}_{2}\left(\mathrm{C}_{2} \mathrm{H}_{5}\right)$ ], which reductively eliminates ethane rather than $\mathrm{H}_{2}$. In this case microcrystals of the complex [(triphos) $\operatorname{IrH}\left(\eta^{1}: \eta^{1}-\mathrm{P}_{4}\right)$ ] were obtained [7]. The presence of the hydrogen tetraphosphide moiety $\mathrm{HP}_{4}$ in the complex IV with $\mathrm{M}=\mathrm{Rh}$ was clearly supported by the NMR spectroscopy [7]. However, to our knowledge, the theoretical study of the entire reaction has not been done so far.

In this work all the stages of the hydrogenation of white phosphorus by the Rh trihydride complex are analyzed on the basis of quantum chemical calculations of all the initial ([(triphos) $\left.\left.\mathrm{RhH}_{3}\right] \mathbf{I}, \mathrm{P}_{4}\right)$, the intermediate ([(triphos) RhH $]$ II, [(triphos) $\left.\mathrm{RhH}\left(\eta^{1}: \eta^{1}-\mathrm{P}_{4}\right)\right] \mathbf{I I I},\left[(\right.$ triphos $\left.) \mathrm{Rh}\left(\eta^{1}: \eta^{2}-\mathrm{HP}_{4}\right)\right] \mathbf{I V a}, \mathbf{I V b}$, and $\mathbf{I V c}$,) and the final ([(triphos) $\left.\left.\mathrm{RhP}_{3}\right] \mathbf{V}, \mathrm{PH}_{3}\right)$ compounds of the reaction from Scheme 1. Special attention is given to clarifying the nature of the Rh-P $\mathrm{P}_{4}$ binding, and the reasons for the distortion (activation) of coordinated $\mathrm{P}_{4}$ molecule. 

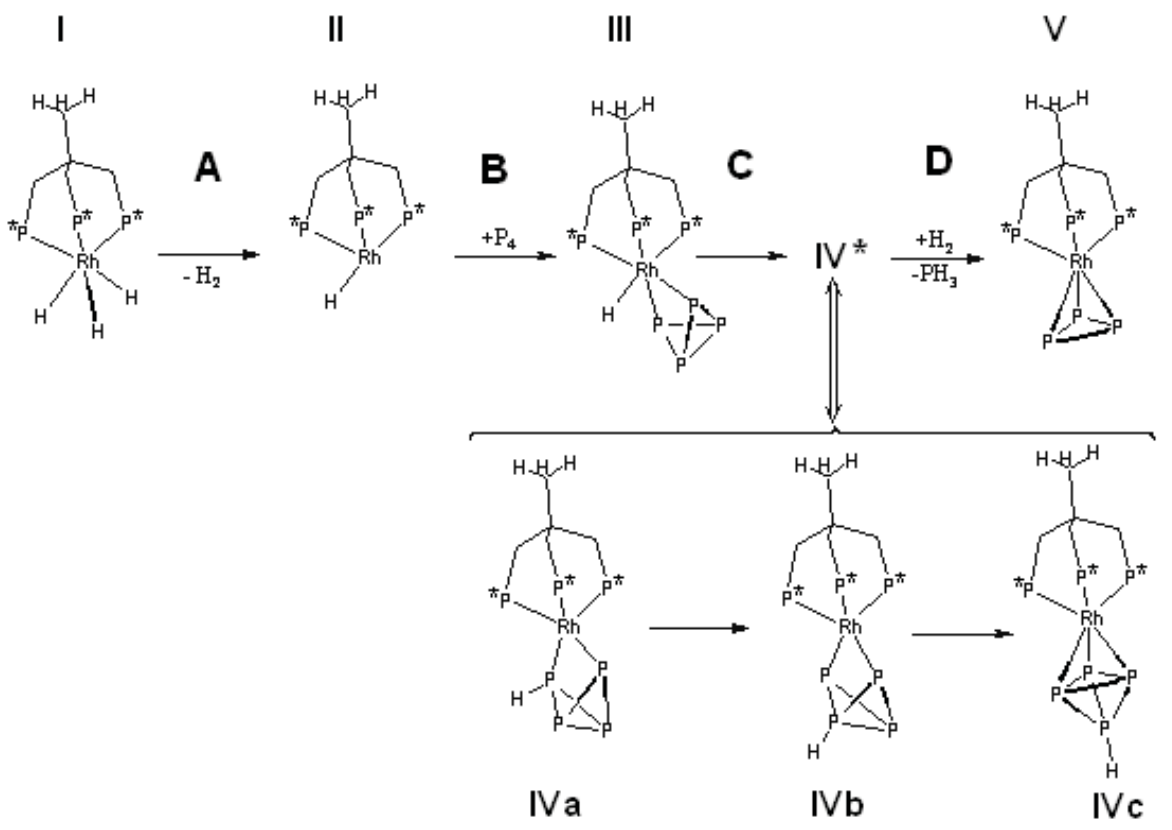

Scheme 1. Reaction of white phosphorus with [(triphos) $\left.\mathrm{RhH}_{3}\right]$.

$\mathrm{P}^{*}$ denotes the phosphorus atoms of the triphos ligand connected with two phenyl rings

\section{Computational details}

All calculations were carried out using the PC GAMESS version [8] of the GAMESS (US) QC package [9]. For each compound considered, a full geometry optimization was performed at ab initio restricted Hartree-Fock (RHF) and density functional (DFT/B3LYP $[10,11]$ ) levels of theory. Ab initio calculations were carried out with the split-valence basis sets for atoms of Rh (3-21G [12]) and P (6-31G(d) [13]) which are directly involved in the reaction, and STO-6G [14] basis set for all other atoms. DFT calculations were performed using the LANL2DZ basis set with non-relativistic effective core potential for Rh, the 6-31G(d) for the phosphorus atoms and 6-31G basis set for all other atoms in the systems. The geometry of the complexes was optimized at their highest possible symmetry: $\mathrm{C}_{3 \mathrm{v}}$ for the systems I, II, IVc, $\mathbf{V}$ and $\mathrm{PH}_{3}$, and $\mathrm{C}_{\mathrm{s}}$ for the III, IVa and IVb. To analyze the possibility of intramolecular hydrogen atom migration, complexes IVa and IVb were also calculated without any symmetry constraints.

In the experimental studies cited above [4-7], the spin states of the complexes are not discussed. To be sure that the total spin of the system does not change during the reaction, all the complexes were calculated for two values of the total spin $(\mathrm{S}=0,1)$, followed by $\mathrm{CI}$ calculations at optimized geometries. Looking ahead, we say that the ground state of all the systems from Scheme 1 is the spin singlet, the triplet states are much higher in energy (more than fifty kcal $/ \mathrm{mol}$ ). Therefore, further discussion refers only to the results of calculations of singlet states of the complexes.

\section{Results and discussion}

\subsection{The $\left[(\right.$ triphos $\left.) \mathrm{RhH}_{3}\right](\mathrm{I})$ and $\left[(\right.$ triphos $\left.) \mathrm{Rh}_{3}\right](\mathrm{V})$ complexes}

The geometry optimization of the complexes $\mathbf{I}$ and $\mathbf{V}$ was carried out in the assumption that the spatial nuclear configuration of them corresponds to the $\mathrm{C}_{3 \mathrm{v}}$ point group of symmetry. These compounds contain three groups of three equivalent atoms: the three phosphorus atoms of the tripodal ligand, the three phosphorus atoms of a triangular $\mathrm{P}_{3}$ unit (V) or three hydrogen atoms linked to the metal in (I), and the three hydrogen atoms of the methyl group. For both compounds, we fully optimize the geometries of the four possible spatial structures, corresponding to the different mutual orientation of these three groups of equivalent atoms. Results of calculation are presented in table 1. One can see that the conformations labeled as "a" are the global minima for both systems. They correspond to the staggered mutual orientation of the two group of atoms linked to the metal. The energies of configuration with their eclipsed orientation (c) are higher in the energy by the values of $10.8 \mathrm{kcal} / \mathrm{mol}$ for the $\mathbf{I}$ and $14.9 \mathrm{kcal} / \mathrm{mol}$ for the $\mathbf{V}$. The energy barrier to rotation of the methyl group is low (compare the structures "b" and "a"). 
Total energies $\left(E\right.$, hartree) and the relative energies $(\Delta E, \mathrm{kcal} / \mathrm{mol})$ of four possible structures of $\mathrm{C}_{3 \mathrm{v}}$ symmetry of the I and $\mathrm{V}$ complexes a), b), c)

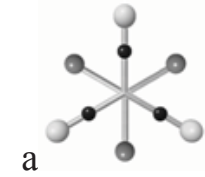

I $\quad E \quad \mathbf{- 7 2 6 4 . 6 4 9 4}$

$\Delta E$

V $E$

0.

$\mathbf{- 8 2 8 5 . 2 2 2 3}$

0.

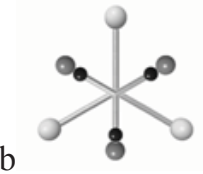

$-7264.6430$

4.0

$-8285.2154$

4.3

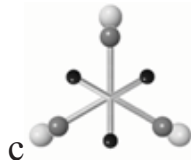

$-7264.6322$

10.8

$-8285.1986$

14.9

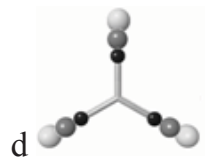

$-7264.6237$

16.1

$-8285.1896$

20.5

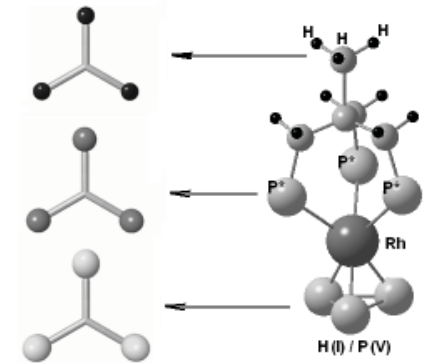

a) Results of RHF calculations

b) The symmetry axis $\mathrm{C}_{3}$ in figs. a-d is perpendicular to the plane of the figures.

c) White circles represent the hydrogen atoms in (I) or the triangular $\mathrm{P}_{3}$ unit in $(\mathbf{V})$, gray circles - phosphorus atoms $\mathrm{P}^{*}$ of the tripodal ligand, and black circles - the hydrogen atoms of the methyl group

The most relevant calculated geometry parameters for considered complexes in the lowest energy configurations ("a" from Table 1) are summarized in Table 2. The available experimental data for the $\left[(\right.$ triphos $\left.) \mathrm{RhP}_{3}\right]$ system are also presented. As can be seen, the method used in the present work provides structural parameters which are in close agreement with the experimental values.

Table 2

Selected geometry parameters for compounds I and V (bond lengths in $\AA$ and bond angles in degrees)

\begin{tabular}{|c|c|c|c|c|c|c|c|}
\hline \multirow[t]{2}{*}{ Parameters } & \multicolumn{2}{|c|}{$\mathbf{I}$} & \multicolumn{3}{|c|}{$\mathbf{V}$} & \multicolumn{2}{|c|}{ Atomic designation } \\
\hline & HFR & DFT & HFR & DFT & exp.[15] & I & V \\
\hline $\mathrm{Rh}-\mathrm{P}^{*}$ a) & 2.53 & 2.38 & 2.52 & 2.39 & 2.29 & & \\
\hline $\mathrm{Rh}-\mathrm{H}_{1}$ & 1.56 & 1.59 & --- & --- & --- & & \\
\hline $\mathrm{Rh}-\mathrm{P}_{1}$ & --- & --- & 2.47 & 2.48 & 2.42 & & \\
\hline $\mathrm{H}_{1}-\mathrm{H}_{1}$ & 2.05 & 2.03 & --- & --- & --- & & \\
\hline $\mathrm{P}_{1}-\mathrm{P}_{1}$ & --- & --- & 2.24 & 2.19 & 2.15 & & \\
\hline$\angle \mathrm{P}^{*}-\mathrm{Rh}-\mathrm{P}^{*}$ & 88.53 & 91.30 & 89.25 & 91.90 & 91.25 & & \\
\hline$\angle \mathrm{H}_{1}-\mathrm{Rh}-\mathrm{H}_{1}$ & 81.39 & 79.39 & --- & --- & --- & & \\
\hline$\angle \mathrm{P}_{1}-\mathrm{Rh}-\mathrm{P}_{1}$ & --- & --- & 54.17 & 52.28 & 52.86 & & \\
\hline
\end{tabular}

a) A-B denotes the interatomic distance

\subsection{The intermediate $\left[(\right.$ triphos $\left.) \operatorname{RhH}\left(\eta^{1}: \eta^{1}-P_{4}\right)\right]$ complex. $P_{4}$ activation}

As mentioned in the Introduction, the iridium analogue of transition complex III, [(triphos) $\left.\operatorname{IrH}\left(\eta^{1}: \eta^{1}-\mathrm{P}_{4}\right)\right]$, was isolated experimentally [7]. It is obtained by removal of the hydrogen molecule from the complex I with formation of the transient complex II and simultaneous addition of $\mathrm{P}_{4}$ molecule.

We have considered two possibilities for $\mathrm{P}_{4}$ addition to the complex II: in the first case the geometry of this complex was optimized, and in the second one its structure was derived from the complex $\mathbf{I}$ by simple removing of two hydrogen atoms. For every case, three modes of approaching the $\mathrm{P}_{4}$ molecule to the complex were considered: coordination by the vertex of the tetrahedron, by its edge, and by its plane.

Optimized structure of II has $\mathrm{C}_{3 \mathrm{v}}$ symmetry in which the remaining hydrogen atom is located on the threefold symmetry axis, i.e. corresponds to the case when the system has time to relax. Calculations showed that in this case none of the three ways of approaching of $\mathrm{P}_{4}$ molecule to the complex II leads to the complex III.

In the second case the remaining hydrogen atom is in the same position as in the complex $\mathbf{I}$. When $\mathrm{P}_{4}$ approaches to the complex II by the vertex of the tetrahedron, its geometry is not changed, and $\mathrm{M}-\mathrm{P}_{4}$ bond is not formed (compare the initial structure IIIa with the optimized one IIId in Fig. 1). Geometry optimization of the other two structures (approaching of $\mathrm{P}_{4}$ by the edge of the tetrahedron (IIIb) and by its plane (IIIc)) results in the same stable complex IIIe (Fig. 1). 


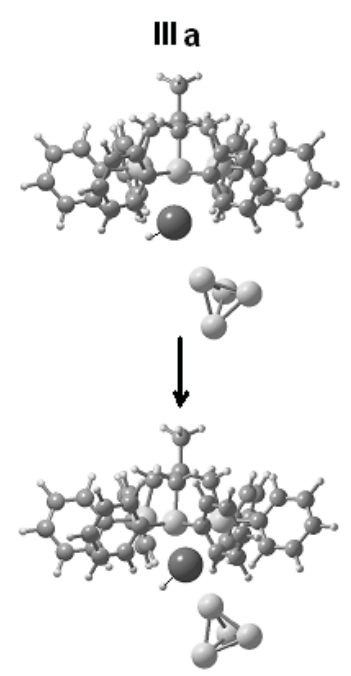

III d

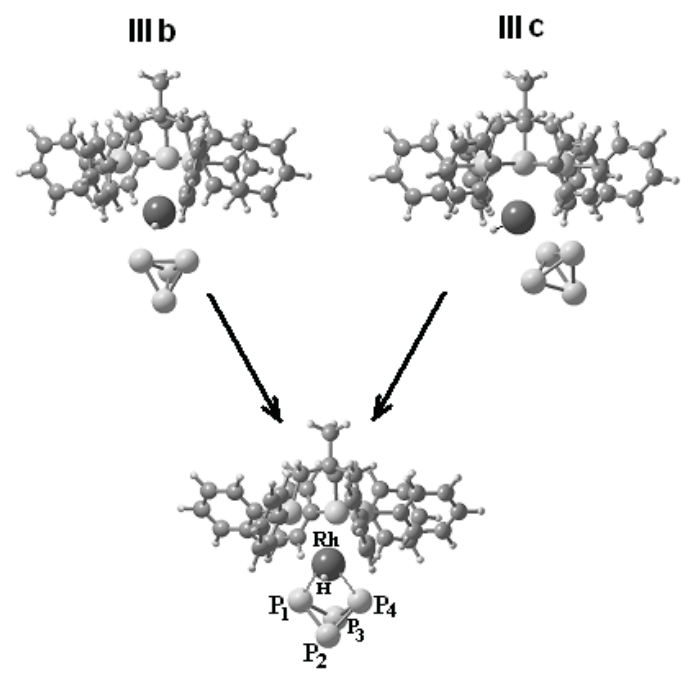

IIIe

Fig. 1. Different modes of approaching the $\mathrm{P}_{4}$ molecule to the complex [(triphos)RhH]: coordination by the vertex of the tetrahedron (III a), by its edge (III b), and by its plane (III c)

It is seen (Fig. 1, IIIe) that the geometrical structure of $\mathrm{P}_{4}$ is significantly changed by its coordination to the complex: one of the $\mathrm{P}-\mathrm{P}$ bonds is broken, and the tetrahedron $\mathrm{P}_{4}$ is opened to form the butterfly geometry. Calculated geometrical parameters for the free tetrahedron $\mathrm{P}_{4}$ molecule, for its reduced form $\mathrm{P}_{4}$ - and for the coordinated (in IIIe) $\mathrm{P}_{4}$ are presented in Table 3. The data from the Table 3 show that geometrical parameters of coordinated $\mathrm{P}_{4}$ molecule have almost the same values as in the reduced form $\mathrm{P}_{4}$.

Table 3

Calculated geometrical parameters for the free $\mathbf{P}_{4}$, for its reduced form $\mathbf{P}_{4}^{-}$, and for the coordinated $\mathbf{P}_{4}$ molecule (bond lengths in $\AA$ and bond angles in degrees)

\begin{tabular}{lccc}
\hline & $\mathrm{P}_{4}$ free & $\mathrm{P}_{4}^{-}$ & $\mathrm{P}_{4}^{\text {coord }}($ III e $)$ \\
$R\left(\mathrm{P}_{1}-\mathrm{P}_{4}\right)$ & 2.19 & 2.82 & 2.95 \\
$R\left(\mathrm{P}_{2}-\mathrm{P}_{3}\right)$ & 2.19 & 2.19 & 2.22 \\
$R\left(\mathrm{P}_{1} / \mathrm{P}_{4}-\mathrm{P}_{2} / \mathrm{P}_{3}\right)$ & 2.19 & 2.23 & 2.28 \\
$\operatorname{dih} \angle \mathrm{P}_{1} \mathrm{P}_{2} \mathrm{P}_{3}-\mathrm{P}_{4} \mathrm{P}_{2} \mathrm{P}_{3}$ & 70.53 & 94.66 & 95.25 \\
$\mathrm{n}\left(\mathrm{P}_{1}-\mathrm{P}_{4}\right)^{\left.\mathrm{b}_{2}\right)}$ & 0.97 & 0.45 & 0.13 \\
$\mathrm{n}\left(\mathrm{P}_{2}-\mathrm{P}_{3}\right)$ & 0.97 & 0.96 & 0.89 \\
$\mathrm{n}\left(\mathrm{P}_{1} / \mathrm{P}_{4}-\mathrm{P}_{2} / \mathrm{P}_{3}\right)$ & 0.97 & 0.94 & 0.81 \\
\hline$\left.{ }^{a}\right)$ &
\end{tabular}

In our recent work [17] it was shown that the butterfly geometry of the coordinated $\mathrm{P}_{4}$ molecule is due to the JahnTeller effect induced by the charge transfer to its triple degenerate excited state. In analysing the electronic redistribution details in the $\left[\right.$ (triphos) $\left.\mathrm{RhH}\left(\eta^{1}: \eta^{1}-\mathrm{P}_{4}\right)\right]$ complex IIIe it seems appropriate to use the definition of the ligand binding suggested by Bersuker in the monograph [18]. In the MO terminology "the multiplicity of the orbital bonding (mono-, di-, and multiorbital) equals the number of complex-ligand bonding MOs uncompensated by the antibonding orbitals" [18]. It follows from this definition that the electron charge transfer to and from the ligand is due to formation of such uncompensated bonding molecular orbitals of the entire complex.

A molecular orbital energy-level scheme of the active valence zone of the whole $\left[(\right.$ triphos $\left.) \operatorname{RhH}\left(\eta^{1}: \eta^{1}-\mathrm{P}_{4}\right)\right]$ complex and that of its fragments, [(triphos)RhH] and $\mathrm{P}_{4}$, is given in Fig. 2. Consider first of all the changes of the molecular orbitals of $\mathrm{P}_{4}$ due to its coordination. As shown above, the tetrahedron $\mathrm{P}_{4}$ is distorted significantly by coordination to the complex. The symmetry of molecule decreases, which causes the splitting of its degenerated MOs. In particular, in the complex IIIe with the point group $\mathrm{C}_{\mathrm{s}}$ the empty antibonding triple degenerate $\mathrm{t}_{1}$-MO splits into the two MOs of $a^{\prime \prime}$ symmetry and one $a^{\prime}$-MO. When forming the complex, these MOs of $\mathrm{P}_{4}$ molecule interact with appropriate orbitals of the $\mathrm{Rh}$ atom, giving rise to the $\mathrm{Rh}-\mathrm{P}_{4}$ bonding. 


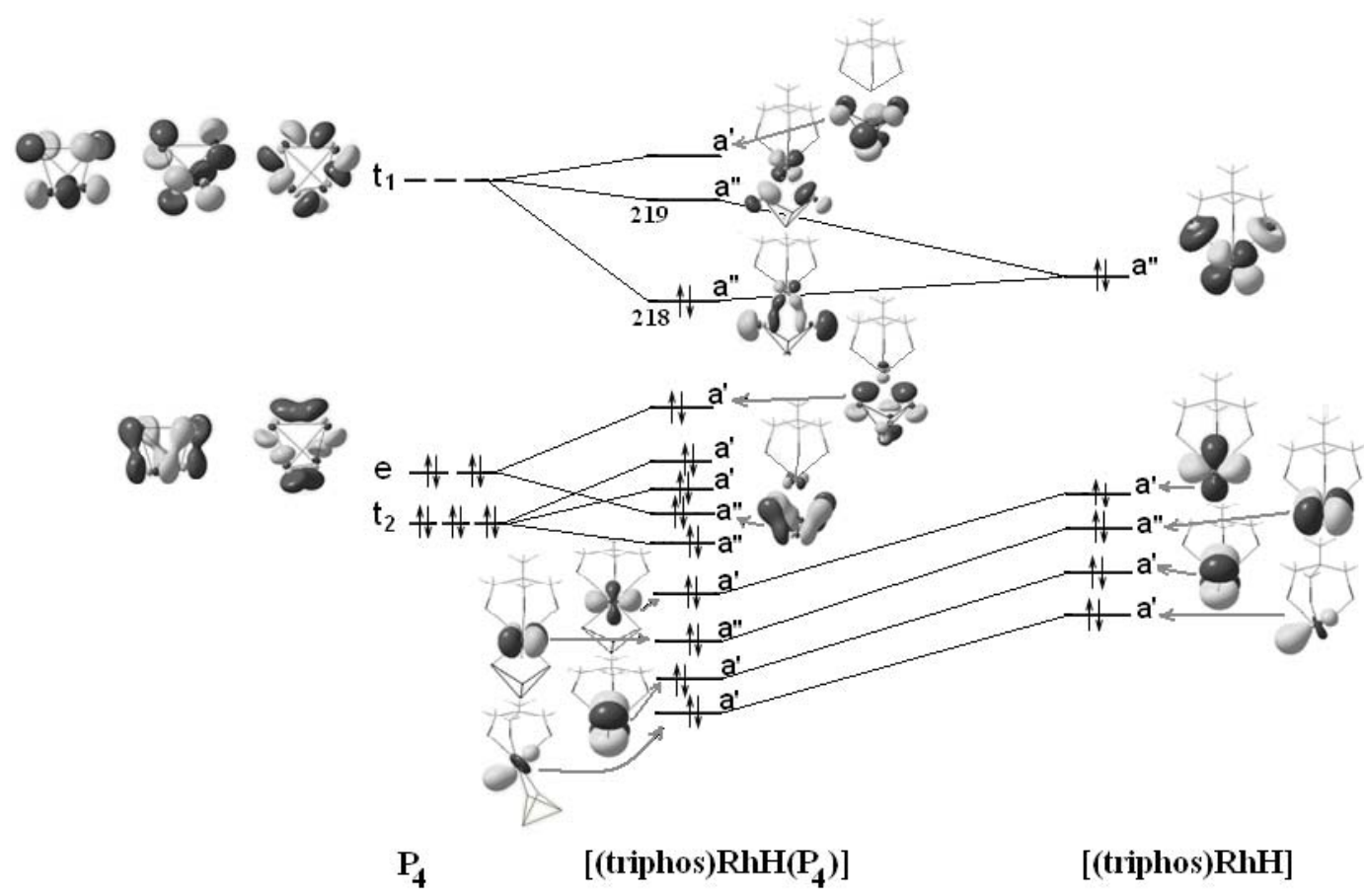

Fig. 2. MO energy-level scheme for bonding between $\mathrm{P}_{4}$ and [(triphos)RhH]

One can see from fig. 2 that only one bonding MO (218 $\left.\boldsymbol{a}^{\prime \prime}\right)$ provides the Rh- $\mathrm{P}_{4}$ binding, being uncompensated by antibonding orbital (i.e. corresponding antibonding MO $219 \boldsymbol{a}^{\prime \prime}$ is not occupied). Therefore the Rh- $\mathrm{P}_{4}$ bonding in the studied complex can be classified as mainly mono-orbital one. This $\pi$-type MO is composed from the filled $\boldsymbol{a}^{\prime \prime} \mathrm{MO}$ of the complex II which is mainly $4 d_{\mathrm{xz}} \mathrm{AO}$ of the atom of $\mathrm{Rh}$ (see on the right side in Fig. 2) and the appropriate component

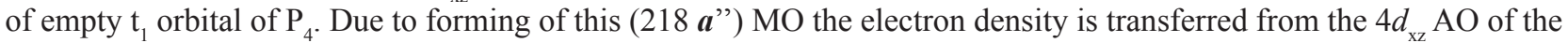
$\mathrm{Rh}$ to the unoccupied $t_{1}$ orbital of $\mathrm{P}_{4}$ (the $\pi$-type back donation) triggering the JTE $t_{2}$ type distortion [18] that result in the butterfly geometry of $\mathrm{P}_{4}$. The orbital charge transfer is quite significant, $\mathrm{D} q=0.68 \overline{\mathrm{e}}$.

\subsection{Intramolecular hydrogen atom migration}

To analyze the possibility of intramolecular hydrogen atom migration from the metal to the phosphorus, the geometry optimization of all the complexes IVa, IVb and IVc from Scheme 1 corresponding to different types of the $\mathrm{P}-\mathrm{H}$ bonding was carried out. Calculated geometry parameters and the values of the total energies are summarized in Table 4.

Table 4

Total energies (E, hartree), interatomic distances A-B ( $\AA$ ) and bond orders (in parentheses) for intermediate compounds III and IV

\begin{tabular}{|c|c|c|c|c|c|c|c|c|}
\hline & \multicolumn{2}{|c|}{ III } & \multicolumn{2}{|c|}{ IVa } & \multicolumn{2}{|c|}{ IVb } & \multicolumn{2}{|c|}{ IVc } \\
\hline & $\mathrm{HFR}^{\text {a) }}$ & $\mathrm{DFT}^{\mathrm{b})}$ & $\mathrm{HFR}^{\mathrm{a})}$ & $\mathrm{DFT}^{\mathrm{b})}$ & $\mathrm{HFR}^{\mathrm{a})}$ & $\mathrm{DFT}^{\mathrm{b})}$ & $\mathrm{HFR}^{\mathrm{a})}$ & $\mathrm{DFT}^{\mathrm{b})}$ \\
\hline E & -0.4570 & -0.7679 & -0.4617 & -0.7702 & -0.4654 & -0.7720 & -0.3618 & -0.7030 \\
\hline Rh- $P_{1}$ & $2.46(0.54)$ & 2.42 & $3.32(0.00)$ & 3.16 & $2.57(0.45)$ & 2.47 & $2.65(0.67)$ & 2.47 \\
\hline $\mathrm{Rh}-\mathrm{P}_{4}$ & $2.46(0.54)$ & 2.42 & $2.57(0.30)$ & 2.37 & $2.57(0.45)$ & 2.47 & $4.51(0.05)$ & 2.87 \\
\hline $\mathrm{P}_{1}-\mathrm{P}_{4}$ & $3.09(0.13)$ & 2.87 & $3.37(0.08)$ & 3.20 & $3.19(0.00)$ & 3.05 & $2.59(0.74)$ & 2.13 \\
\hline $\mathrm{P}_{1}-\mathrm{P}_{2}$ & $2.37(0.81)$ & 2.26 & $2.38(0.82)$ & 2.27 & $2.37(0.86)$ & 2.27 & $2.31(0.57)$ & 3.09 \\
\hline $\mathrm{P}_{1}-\mathrm{P}_{3}$ & $2.39(0.81)$ & 2.27 & $2.38(0.83)$ & 2.27 & $2.25(0.81)$ & 2.20 & $2.31(0.57)$ & 3.09 \\
\hline $\mathrm{P}_{2}-\mathrm{P}_{3}$ & $2.32(0.88)$ & 2.18 & $2.34(0.88)$ & 2.19 & $3.17(0.05)$ & 3.07 & $2.31(0.57)$ & 3.09 \\
\hline $\mathrm{P}_{4}-\mathrm{P}_{2}$ & $2.37(0.81)$ & 2.26 & $2.37(0.77)$ & 2.27 & $2.37(0.86)$ & 2.27 & $2.59(0.74)$ & 2.13 \\
\hline $\mathrm{P}_{4}-\mathrm{P}_{3}$ & $2.39(0.81)$ & 2.27 & $2.38(0.79)$ & 2.26 & $2.25(0.81)$ & 2.20 & $2.59(0.74)$ & 2.13 \\
\hline $\mathrm{P}^{\text {coord }}-\mathrm{H}$ & --- & --- & $1.44(0.78)$ & 1.46 & $1.44(0.85)$ & 1.43 & $1.43(0.89)$ & 1.43 \\
\hline
\end{tabular}

a) Values of energy are given relative to -8626.0 a.u.

b) Values of energy are given relative to -4081.0 a.u. 
It is seen from the Table 4 that the lowest in energy structure corresponds to the complex IVb in which the hydrogen atom is bonded not with the nearest (to $\mathrm{Rh}$ ) atom of phosphorus ( $\mathrm{P}_{1}$ or $\mathrm{P}_{4}$ from Fig. 1), but with one of the distant atoms $\mathrm{P}_{2}$ or $\mathrm{P}_{3}$. Figure 3 depicts the optimized structures of all the intermediate compounds and the most probable path of the hydrogen atom migration from rhodium to phosphorus. Unfortunately, due to the complexity of the system, we were unable to localize transition states corresponding to the hydrogen atom transfer from the Rh to the nearest phosphorus atoms $(\mathbf{I I I} \rightarrow \mathbf{I V a})$, and then to the distant atoms $\mathrm{P}_{2}$ or $\mathrm{P}_{3}(\mathbf{I V a} \rightarrow \mathbf{I V b})$. The structure denoted as TS in Fig.3 is obtained by point-by-point calculations of the complex at different positions of the hydrogen between the atoms $\mathrm{P}_{1}$ and $\mathrm{P}_{2}$, without its further optimization. So, the barrier height between the structures IVa and IVb can be regarded only as an estimate. We also calculated the structure IVc as being the "most prepared" for adding to the complex of two hydrogen atoms with subsequent separation of $\mathrm{PH}_{3}$. However, its energy is too high to ensure that this complex could be formed during the reaction.
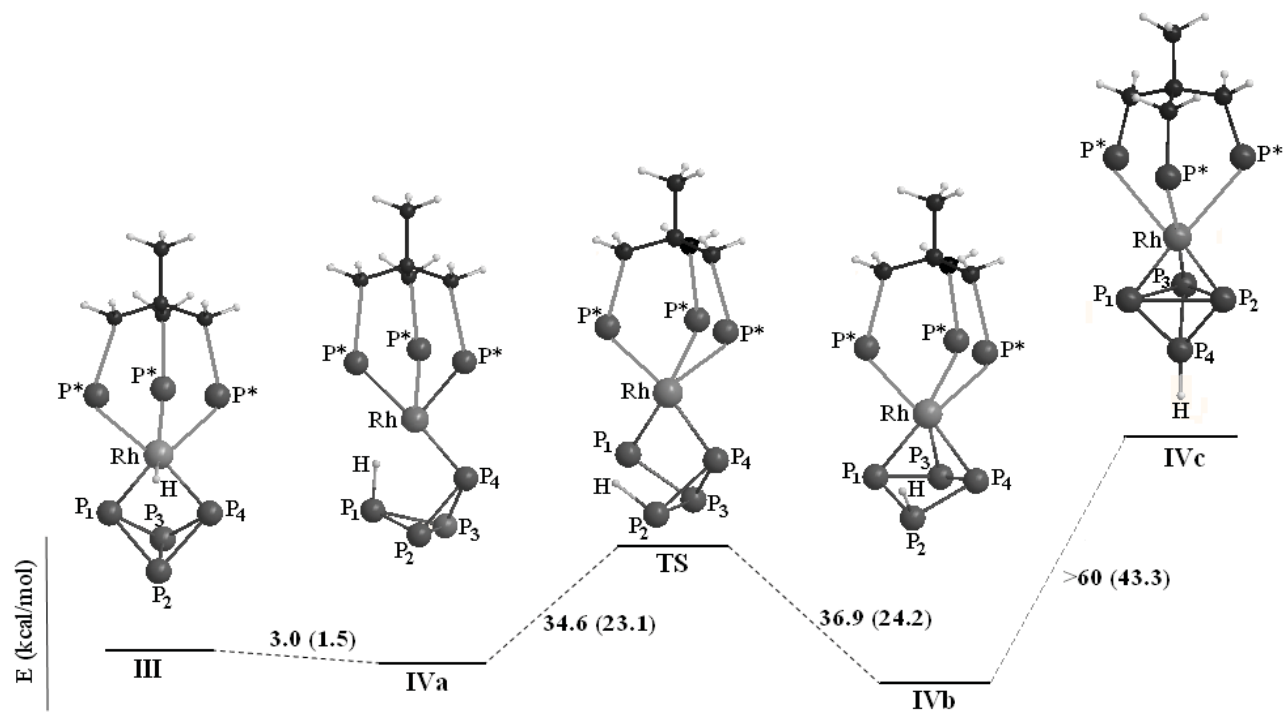

Fig. 3. Energy diagram for the hydrogen atom migration calculated at the RHF and B3LYP (in parentheses) levels of theory

Further addition of two hydrogen atoms to the complexes IVa and IVb and their subsequent optimization leads to the complex [(triphos) $\left.\mathrm{RhP}_{3}\right] \mathbf{V}$ and the phosphane molecule $\mathrm{PH}_{3}$. The energy profile for the entire reaction predicted by both the RHF and DFT levels of theory is presented in Fig. 4. It is seen that generation of the transient complex $\left[\right.$ (triphos) $\left.\mathrm{RhH}\left(\eta^{1}: \eta^{1}-\mathrm{P}_{4}\right)\right]$ III followed by intramolecular hydrogen atom migration from the metal to the phosphorus to yield IV is the energetically favorable process. Every step of the reaction is accompanied by an energy gain, so that the above four-stage reaction mechanism seems to be reasonable.

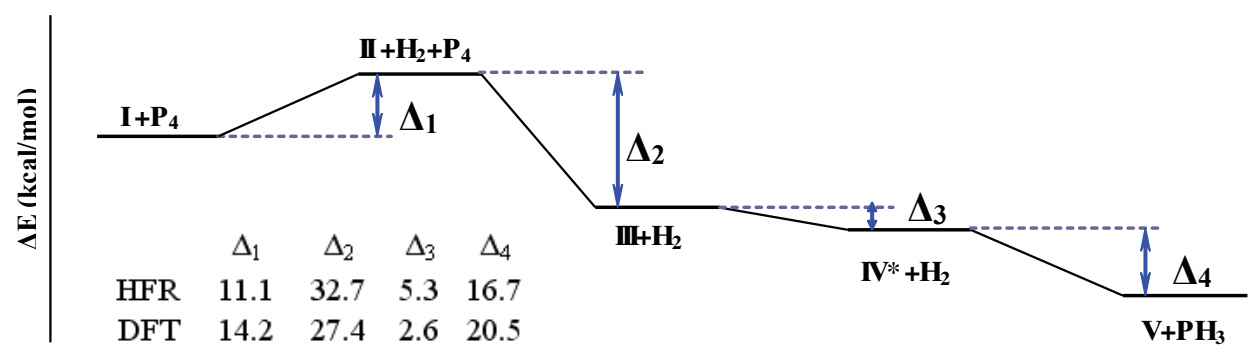

Fig. 4. Calculated energy profile of reaction from Scheme 1 (all values are in $\mathrm{kcal} / \mathrm{mol}$ )

Note that both RHF and DFT calculations give qualitatively the same picture (Figs. 3, 4), differing only in the values of relative energies of the complexes. 


\section{Conclusion}

Our calculations confirm the possibility of activation and direct hydrogenation of white phosphorus to $\mathrm{PH}_{3}$ when promoted by rhodium trihydride complex [(triphos) $\left.\mathrm{RhH}_{3}\right]$. The proposed four-stage mechanism of reaction of $\mathrm{P}_{4}$ with the $\left[(\right.$ triphos $\left.) \mathrm{RhH}_{3}\right]$ resulting in the phosphane and the cyclo- $\mathrm{P}_{3}$ complex $\left[(\right.$ triphos $) \mathrm{M}\left(\eta^{3}-\mathrm{P}_{3}\right]$ seems to be plausible. The generation of the transient complex $\left[(\right.$ triphos $\left.) \mathrm{RhH}\left(\eta^{1}: \eta^{1}-\mathrm{P}_{4}\right)\right]$ followed by intramolecular hydrogen atom migration from the metal to the phosphorus is the energetically favorable process. $\mathrm{P}_{4}$ molecule is activated by its coordination to the above intermediate: one of the P-P bonds $\left(\mathrm{P}_{1}-\mathrm{P}_{4}\right)$ is broken, and the tetrahedron $\mathrm{P}_{4}$ is opened to form the butterfly geometry. The activation is realized due to the one-orbital back donation of electron density from one of the occupied molecular orbitals of the precursor complex [(triphos) $\mathrm{RhH}]$ to the unoccupied antibonding triple degenerate $t_{1}{ }^{*}$-MO of $\mathrm{P}_{4}$.

This work was initiated under the guidance of Professor I.Ya. Ogurtsov and was completed by the authors in his memory.

\section{Acknowledgments}

The authors are grateful to Dr. Gabriel Munteanu and Dr. Viorel Chihaia for the opportunity to carry out calculations on the hpc-icf computer cluster (http://www.hpc-icf.ro/) at the Institute of Physical Chemistry "I.Mugurescu", Bucharest, Romania.

\section{References}

[1] Peruzzini, M.; de los Rios, I.; Romerosa, A.; Vizza, F. Eur. J. Inorg. Chem., 2001, N3, 593-608.

[2] Peruzzini, M.; Gonsalvi, L.; Romerosa, A.; Chem. Soc. Rev., 2005, 34, 1038.

[3] Schoeller, W.W. Inorg. Chem., 2011, 50, 22.

[4] Barbaro, P.; Ienco, A.; Mealli, C.; Peruzzini, M.; Scherer, O.J.; Schmitt, G.; Vizza,F.; Wolmershäuser, G.; Chemistry - A European Journal, 2003, 9, 5195-5210.

[5] Barbaro, P.; Caporali,M.; Ienco,A.; Mealli, C.; Peruzzini, M.; Vizza, F.; Eur. J. Inorg. Chem., 2008, 1392.

[6] Barbaro, P.; Peruzzini, M.; Ramirez, J.A.; Vizza, F. Organometallics, 1999, 18, 4237-4240.

[7] Peruzzini, M.; Ramirez, J.A.; Vizza, F.; Angew. Chem. Int. Ed., 1998, 37, 2255-2257.

[8] Granovsky, Alex A. www http://classic.chem.msu.su/gran/gamess/index.html

[9] Schmidt, M.W., et.al.; J.Comput.Chem., 1993, 14, 1347-1363.

[10] Becke, A.D. J. Phys. Chem., 1993, 98, 5648.

[11] Lee, C.; et al.; Phys. Rev. B, 1988, 37, 785.

[12] Huzinaga, S., Andzelm, J., eds. 1984 Gaussian Basis Sets for Molecular Calculations, Elsevier, Amsterdam.

[13] Dill, J. D.; Pople, J. A.; J. Chem. Phys., 1975, 62, 2921-2923.

[14] Hehre, W.J.; Stewart, R.F.; Pople, J.A.; J. Chem. Phys., 1969, 51, 2657.

[15] Bianchini, C.; Mealli, C.; Meli, A.; Sacconi, L.; Inorg. Chim. Acta, 1979, 37, L543.

[16] Osman, R.; Coffey, P., Van Wazer, J.R.; Inorg. Chem., 1976, 15, 287.

[17] Gorinchoy, N.N.; Balan, I.I.; Bersuker, I.B.; Comput. \& Theor. Chem., 2011, DOI: 10.1016/j. comptc.2011.08.013.

[18] Bersuker, Isaac B. Electronic Structure and Properties of Transition Metal Compounds. Introduction to the Theory, Second Ed.; John Wiley: New York, 2010, Ch. 6.3, p.257. 